\title{
Deficiência intelectual e aquisição matemática: currículo como rede de relações condicionais
}

\author{
Rosana Aparecida Salvador Rossit \\ Celso Goyos
}

\begin{abstract}
Resumo
O presente estudo teve como objetivo analisar a aquisição de relações matemáticas e apresentar um currículo baseado no paradigma de equivalência de estímulos para ensinar deficientes intelectuais a manusear dinheiro. Participaram 11 pessoas com deficiência intelectual, com idade entre nove a 32 anos, de ambos os gêneros, estudantes de escola de Educação Especial. Os estímulos utilizados foram palavras ditadas, numerais impressos, imagens de moedas e notas, componentes da adição, conjunto de moedas, notas e moedas juntas, preços impressos, moedas e notas verdadeiras. Quatro estudos foram conduzidos para o ensino de diferentes relações. O procedimento de ensino foi conduzido através do programa computacional Mestre ${ }^{\circledR}$. Os resultados demonstraram a eficácia do currículo como rede de relações e dos procedimentos utilizados, constatada a aquisição de habilidades complexas num período de tempo reduzido. Uma ampla e complexa rede de relações matemáticas foi adquirida a partir do ensino direto de apenas algumas relações.
\end{abstract}

Palavras-chave: Matemática, currículo, deficiente mental.

\section{Mental retardation and acquisition of mathematics: curriculum as a conditional relation network}

\begin{abstract}
In this study we analyze the acquisition of mathematics relation and present the curriculum based on stimulus equivalence paradigm to teach people with mental retardation how to deal with money. We worked with 11 people with mental retardation, with ages from 09 to 32 years old, both genders, who attended a Special Education School. Stimuli were dictated words, printed numerals, coin and bill pictures, numerals with a plus sign between them, coin sets, coins and bills together, printed prices, actual coins and bills. Four studies were conducted to teach several distinct relations. Teaching procedure was conducted using a computer program named Master. Results showed the efficacy of the curriculum based on a relational network and the procedures used, by the emergence of complex skill acquisition in a reduced period of time. A complex and large mathematics relational network was taught through direct training of few relations.
\end{abstract}

Keywords: Mathematics, curriculum, mentally retarded.

\section{Deficiencia intelectual y adquisición matemática: currícula como red de relaciones condicionales}

\begin{abstract}
Resumen
El presente estudio tuvo como objetivo analizar la adquisición de relaciones matemáticas y presentar una currícula, basada en el paradigma de equivalencia de estímulos, para enseñar a deficientes intelectuales a manejar dinero. Participaron 11 personas con deficiencia intelectual, de edades entre 09 y 32 años, de ambos géneros, estudiantes de colegio de Educación Especial. Los estímulos utilizados fueron palabras dictadas, números impresos, imágenes de monedas y billetes, componentes de adición, conjuntos de monedas, billetes y monedas juntos, precios impresos, monedas y billetes verdaderos. Cuatro estudios fueron dirigidos para la enseñanza de diferentes relaciones. El procedimiento de enseñanza fue conducido por el programa computacional Mestre®. Los resultados demostraron la eficacia de la currícula como red de relaciones y de los procedimientos utilizados, fue constatada la adquisición de habilidades complejas en un lapso de tiempo reducido. Una amplia y compleja red de relaciones matemáticas fue adquirida a partir de la enseñanza directa de apenas algunas relaciones.
\end{abstract}

Palabras-clave: Matematica, curriculum, retrasado mental. 
"Saber matemática é uma necessidade imperativa numa sociedade a cada dia mais complexa e tecnológica, em que se torna difícil encontrar setores em que este conteúdo não esteja presente".

(Teberosky \& Tolchinsky, 2002, p.257)

\section{Introdução}

AMatemática está presente em inúmeras situações do cotidiano. Atividades comuns tais como marcenaria, cozinha, limpeza, escritório e supermercado requerem sistemas de contagem e habilidades de usar e reconhecer numerais. Além dos números serem uma linguagem de medida, eles também são necessários para os comportamentos adaptativos de encontrar um endereço, usar um telefone, "ler" horas de um relógio ou mesmo apreciar um jogo de futebol (Rossit, 2003; Spradlin, Cotter, Stevens, \& Friedman, 1974).

Discussões no âmbito da Educação Matemática apontam a necessidade de adequar o trabalho escolar a uma nova realidade, marcada pela crescente presença desses conteúdos em diversos campos da atividade humana. Essas discussões têm influenciado análises e revisões nos currículos $^{1}$ de Matemática (MEC, 1998).

Embora existam estudos sobre o ensino de matemática naáreadaeducação(Resnick, Wang \&Kaplan, 1973; Teberosky \& Tolchinsky, 2002) e da análise do comportamento (Araújo, 2004; Carmo, 1997; De Lèon, 1998; Green, 1992; Monteiro \& Medeiros, 2002; Prado, 2001; Rossit, 2003; Spradlin \& cols., 1974; Stoddard, Bradley, \& Mcllvane, 1987; Stoddard, Brown, Hurlbert, Manoli, \& Mcllvane, 1989), a questão de como as pessoas adquirem os conceitos matemáticos ainda instiga os pesquisadores a novas investigações.

As inúmeras variáveis que controlam o comportamento matemático precisam ser estudadas de maneira mais aprofundada para esclarecer e revelar os possíveis requisitos e as sequências envolvidas na aquisição de novos repertórios. A escassez de investigações científicas sólidas que expliquem e forneçam subsídios para a compreensão dos processos de ensino-aprendizagem envolvidos fez com que crescesse o interesse em pesquisar a aquisição de conceitos matemáticos na perspectiva da análise do comportamento.

Para delinear um perfil curricular para o ensino de comportamentos matemáticos, pressupõe-se a presença de inúmeros componentes que se relacionam entre si. Diversos elementos que são requisitos essenciais para a aquisição de habilidades com alto grau de complexidade, como é o caso da matemática, estão envolvidos, como os conceitos de números, operações básicas, conceitos monetários, conceitos relacionais de igual-diferente, mais-menos, antesdepois, maior-menor, entre outros.

Rossite Ferreira (2003) explicam que o comportamento matemático é uma subdivisão do comportamento verbal que apresenta um vocabulário aritmético, uma sintaxe, uma estrutura de equações e outros tipos de funções, e

1 O termo "currículo" é entendido como a totalidade de situações de ensino-aprendizagem que estimula o desenvolvimento do aluno, levando-o à aquisição de conhecimentos, habilidades e atitudes. de encadeamento como na contagem, que ocorre tanto na comunicação, como no pensamento. Esse é um comportamento complexo, que pode ser dividido em unidades funcionais menores. Essas unidades podem aparecer como palavras ditadas, figuras, numerais e valores monetários impressos, conjuntos, expressões verbais, expressões numéricas, equações, dinheiro, nomeação, contagem, construção de respostas, entre outras. (p. 13)

O currículo de matemática das escolas, em geral, focaliza o domínio e aplicação dos conceitos matemáticos, operações, fatos matemáticos e resolução de problemas. Embora essas unidades possam inicialmente aparecer separadas em um programa de ensino, na prática, elas tornam-se crescentemente interligadas, como resultado da complexidade das tarefas e da aplicabilidade matemática.

Porém, nas escolas, o conhecimento ainda é interpretado como uma cadeia de raciocínios, que se articulam linearmente (Pires, 2000). A linearidade, que se concretiza numa sucessão de tópicos que devem ser apresentados numa certa ordem, conduz a uma prática educativa fechada, em que há pouco espaço para a criatividade, para a utilização de estratégias metodológicas como a resolução de problemas, para a abordagem interdisciplinar, para o estabelecimento de relações entre os diferentes campos matemáticos. Esse modelo de planejamento de ensino parece influenciar a aquisição de conceitos matemáticos e contribuir para a evidência dos altos índices de dificuldades e de retenção em disciplinas que envolvam cálculos.

É preciso tomar caminhos que possam substituir a linearidade. A proposta de uma estrutura curricular diferente, na qual o conhecimento é organizado como rede de relações ${ }^{2}$, tem se mostrado eficiente para o ensino e aprendizagem de uma diversidade de conteúdos matemáticos, formando um emaranhado de conceitos e classes de estímulos e respostas que se tornam equivalentes entre si (Rossit, 2003; Araújo, 2004).

No contexto nacional atual, com a expansão da noção de necessidades especiais, contemplando dificuldades em diferentes níveis, é importante tanto o desenvolvimento de metodologias diversificadas de ensino como de procedimentos flexíveis de modo a atender à diversidade dos alunos. Assim, surge a preocupação com um processo de ensino-aprendizagem suficiente e eficaz que atenda às necessidades educacionais dessa população em especial.

A Psicologia tem proporcionado contribuições relevantes no âmbito do ensino-aprendizagem. Uma das vertentes que tem se preocupado com tal temática é a Análise do Comportamento, que se caracteriza pelo estudo objetivo do comportamento dos organismos, levando em consideração o seu ambiente físico, social, cultural e sua história como influências nas ações dos organismos.

A Análise do Comportamento humano visa à previsão e ao controle do comportamento. Para isso, o comportamento é investigado e variáveis são manipuladas visando ao

2 Rede de relações é um conjunto de estímulos e desempenhos que mapeiam o território de equivalência de estímulos (Stromer, Mackay \& Stoddard, 1992). 
entendimento de sua influência sobre tal comportamento. A partir de tais investigações, torna-se possível desenvolver procedimentos de ensino para populações diferenciadas como, por exemplo, as pessoas com deficiência intelectual. Sendo assim, ao conhecer as variáveis envolvidas no processo de ensino-aprendizagem, essas se tornam passíveis de manipulação e o comportamento almejado pode ser inserido com maior controle.

Um planejamento baseado na Análise do Comportamento requer a análise de cada comportamento e sua execução necessita de avaliação contínua a fim de que decisões acerca da continuidade ou redirecionamento do ensino sejam tomadas de acordo com a especificidade de cada caso (Rossit, 2004).

Ao planejar um método de ensino fundamentado nos princípios da Análise do Comportamento, deve-se partir do pressuposto de que o repertório de conhecimento de cada indivíduo é único. Nesse sentido, cabe ao educador investigar e conhecer o repertório de entrada dos alunos para que o ensino possa ser planejado com vistas a atender às suas necessidades educacionais. $\mathrm{O}$ ensino deve ocorrer dos elementos básicos aos mais complexos. O grau de complexidade deve ser aumentado gradativamente de acordo com as condições individuais, assim como reduzir gradativamente os níveis de apoio. A avaliação e o planejamento devem ocorrer de forma contínua e simultânea à aplicação dos novos conteúdos. A aquisição de novas relações entre estímulos e entre estímulos e respostas deve ser analisada através das respostas apresentadas na situação planejada de ensino. Se a aprendizagem ocorrer, o educador poderá prosseguir com o seu planejamento, se houver manifestações de dificuldades, o planejamento deve ser reavaliado e novas decisões devem ser tomadas.
Nesta estrutura diferente, as relações entre repertórios presentes e entre aqueles a serem adquiridos descartam a necessidade da presença de todos os pré-requisitos no repertório do indivíduo antes de se introduzir um novo conteúdo. As relações são entendidas como coadjuvantes, ou seja, elas podem ser ensinadas separadamente e aprendidas independentemente, propiciando a expansão da rede de relações. Essa evidência com relação ao processo de ensino-aprendizagem indica que as relações são independentes e que o ensino pode ocorrer a partir de qualquer relação, não sendo necessário percorrer uma sequência fixa, linear (Rossit, 2003).

Essa concepção proporciona benefícios para o ensino de pessoas que apresentam características peculiares de aprendizagem, como é o caso da deficiência intelectual, pois, a partir da identificação das relações presentes no repertório individual, insere-se gradativamente os novos estímulos que irão se relacionar com o conhecimento já consolidado, expandindo a rede de relações e de conhecimento.

Assim, o objetivo do presente estudo foi analisar a aquisição de relações matemáticas e propor um currículo baseado no paradigma de equivalência de estímulos para ensinar deficientes intelectuais a manusear dinheiro.

\section{Método}

Participantes. Foram selecionadas 11 pessoas com deficiência intelectual, com idade entre nove e 32 anos, de ambos os gêneros, que frequentavam uma escola de educação especial em uma cidade do interior de São PauloSP e sem experiência anterior em pesquisas que utilizaram procedimentos de escolha de acordo com o modelo, para

Tabela 1. Caracterização dos participantes

\begin{tabular}{|c|c|c|c|c|c|c|c|}
\hline \multirow{2}{*}{ Participantes } & \multirow{2}{*}{$\begin{array}{l}\text { Idade } \\
\left(^{*}\right)\end{array}$} & \multirow{2}{*}{ Sexo } & \multirow{2}{*}{ Diagnóstico } & \multirow{2}{*}{$\begin{array}{c}\text { I. Mental } \\
\left({ }^{*}\right)\end{array}$} & \multicolumn{2}{|c|}{ Q.I. } & \multirow{2}{*}{$\begin{array}{c}\text { Tempo } \\
\text { Escolarização (*) }\end{array}$} \\
\hline & & & & & WISC(**) & I. Mental & \\
\hline MRO & 32 & $\mathrm{~F}$ & D.A. e D.M. & 10,6 & 54 & Moderada & 28,5 \\
\hline PED & 12,2 & M & S. Down & 8,1 & 63 & Leve & 12 \\
\hline $\mathrm{ACA}$ & 21,3 & $\mathrm{~F}$ & S. Down & 9,1 & 54 & Moderada & 17,5 \\
\hline ROT & 18,3 & M & D.M. & 9,2 & 51 & Moderada & 13 \\
\hline DUD & 14,8 & M & D.M. & 5,1 & 41 & Moderada & 12 \\
\hline GBF & 19,6 & M & D.M. & 4,6 & Não Avaliável & Moderada & 15 \\
\hline GUA & 16 & M & D.M. & 5,2 & Não Avaliável & Moderada & 12 \\
\hline $\mathrm{ROA}$ & 17,1 & M & S. Martin-Bell & 4,6 & Não Avaliável & Severa & 14,5 \\
\hline BRS & 12,5 & $\mathrm{~F}$ & S. Down & 3,2 & Não Avaliável & Severa & 10 \\
\hline POL & 18,3 & $\mathrm{~F}$ & D.M. & 4,6 & Não Avaliável & Profunda & 16 \\
\hline JES & 9,10 & $\mathrm{~F}$ & S. Down & 5,1 & 46 & Moderada & 6 \\
\hline \multicolumn{3}{|c|}{$\begin{array}{l}\text { (*) Anos, meses } \\
(* *) \text { WISC - Aplicado em } 2003 \\
\text { D.A. - Deficiência Auditiva } \\
\text { Fonte: Elaboração dos autores }\end{array}$} & $\begin{array}{l}\text { D.M. - Defi } \\
\text { Q.I. - Quoef } \\
\text { I. Mental - I }\end{array}$ & $\begin{array}{l}\text { iciência Men } \\
\text { ficiente de I } \\
\text { Idade Menta }\end{array}$ & $\begin{array}{l}\text { ntal } \\
\text { nteligência }\end{array}$ & & \\
\hline
\end{tabular}


participar de um ou mais estudos. Como critério, incluiuse a presença de habilidade para comunicar-se oral ou gestualmente e o interesse em realizar atividades no computador. Foi obtido o consentimento livre e esclarecido dos pais ou responsáveis legais. A Tabela 1 apresenta os dados de caracterização dos participantes.

Material e Ambiente Experimental. O ambiente experimental contendo um microcomputador com monitor colorido, kit multimídia e programa computacional Mestre $®$ (Goyos \&Almeida, 1994)foi utilizado para programar, conduzir, registrar e arquivar os dados, e montado em uma sala da escola, cedida exclusivamente para o desenvolvimento da pesquisa, medindo aproximadamente $2,5 \mathrm{~m} \times 3,0 \mathrm{~m}$. Outros materiais como mesa, cadeira, fichas plásticas, um condutor plástico para liberação das fichas e um recipiente plástico transparente para armazenamento de fichas também foram utilizados. As tarefas de discriminação condicional foram apresentadas pelo computador.

Estímulos Experimentais. Foram utilizados, como estímulos visuais, os algarismos "1", "5", "10", "25", "50" e "100", formatados em fonte Times, cor preta, cujos tamanhos variavam conforme a cor de fundo da tela: tamanho 110 , algarismos apresentados contra um fundo branco; ou tamanho 48 , contra o fundo azul. Os preços impressos em valores decimais ("0,01"; " 0,05 "; " 0,10 "; " 0,25 "; " 0,50 "; " 1,00 "; " 5,00 "; "10,00"; "50,00" e "100,00") foram formatados no tamanho 48. As figuras das moedas de $1,5,10,25$ e 50 centavos e as figuras das notas de 1, 5, 10, 50 e 100 reais foram digitalizadas através de scanner. Esses valores foram escolhidos por corresponderem às moedas e notas em circulação. As cores originais foram mantidas tanto para as moedas como para as notas. Para as moedas, o tamanho original foi conservado e, para as notas, o tamanho foi reduzido nas dimensões de $2,0 \mathrm{~cm}$ por $4,0 \mathrm{~cm}$. Os conjuntos de moedas ou notas foram preparados com um, dois, três ou cinco elementos (moedas e/ou notas) em tamanho reduzido, organizados dentro do espaço de $4,0 \mathrm{~cm}$ por $4,0 \mathrm{~cm}$. O tamanho aproximado da moeda no conjunto foi de $1,5 \mathrm{~cm}$ de diâmetro e, para as notas, foi de $2,5 \mathrm{~cm}$ por $1,2 \mathrm{~cm}$. Os estímulos visuais foram preparados no programa Photoshop, salvos no formato ".pic" e adicionados à pasta de imagens do Mestre®. Nas situações de testes, foram acrescentados outros estímulos auditivos e visuais com valores diferentes $(2,6,11,35,60,75)$, além de moedas e notas verdadeiras.

Como estímulos auditivos, foram utilizadas as instruções verbais e os nomes dos numerais, moedas, notas, preços ou conjuntos correspondentes aos estímulos visuais. As vozes foram gravadas no equipamento MacRecorder, através do programa Sound Edit. Cada arquivo foi salvo com a extensão ".aif" e armazenado na pasta de sons do Mestre ${ }^{\circledR}$. O estímulo auditivo era apresentado simultaneamente com um quadrado branco medindo $4,0 \mathrm{~cm}$ por $4,0 \mathrm{~cm}$ na metade superior da tela do computador.

Procedimentos de Coleta de Dados. Foi aplicado, inicialmente, um procedimento para identificar as preferências individuais através do levantamento de itens. Em seguida, os testes preliminares mapearam o repertório de entrada dos participantes e um treino preparatório de identidade com figuras familiares foi conduzido, com a finalidade de inserir comportamentos essenciais para responder condicionalmente: olhar para o estímulo modelo, tocá-lo como uma resposta de observação, olhar para os estímulos escolha, selecionar um deles em resposta ao modelo e receber consequências para escolhas corretas e incorretas. Quatro estudos foram conduzidos e cada um deles teve como delineamento: um pré-teste para definição da linha de base, o treino de relações condicionais e a aplicação de testes imediatos para verificar a emergência e a generalização de relações para diferentes valores, conjuntos e situações. Testes de manutenção foram aplicados no terceiro e no sexto mês após o término de cada experimento. As especificidades de cada estudo estão detalhadas a posteriori.

Levantamento de Preferência por Itens. Nesse procedimento, descrito detalhadamente em Escobal e Goyos (2008), foram utilizados dez brinquedos ou objetos correspondentes à idade cronológica dos participantes, identificados junto a eles a partir das respostas às seguintes perguntas: O que você mais gosta de fazer para se divertir? Quais os jogos de que você mais gosta? Quais os personagens de filme/desenho de que você mais gosta? Você faz alguma coleção? O que você coleciona? Após as informações coletadas, foi elaborado um protocolo com as combinações para a apresentação dos itens. Os itens foram apresentados, de dois em dois, acompanhados da seguinte instrução: "De qual você gosta mais? Deste (aponta para um) ou deste (aponta para o outro)?". As escolhas foram registradas em protocolos individuais. Os itens escolhidos foram hierarquizados e recombinados de acordo com a preferência (número de escolhas feitas) e reapresentados. As preferências finais foram definidas e classificadas: Nível Alto (NA) - três ou mais escolhas; Nível Médio (NM) - duas escolhas; Nível Baixo (NB) - uma escolha; e Sem Preferência (SP) - nenhuma escolha. Três itens, correspondentes aos três níveis de menor preferência, foram inicialmente disponibilizados para que o participante pudesse trocar suas fichas, após terem alcançado critério de $90 \%$ de desempenho correto. Os itens com alto nível de preferência só foram disponibilizados ao final de cada estudo durante situação de compra simulada, na qual foi possível avaliar a habilidade do participante em manusear o dinheiro para construir a resposta a partir do preço impresso.

Testes Preliminares de Levantamento de Repertório. Para avaliar os comportamentos matemáticos presentes no repertório de cada participante, alguns testes foram aplicados com materiais concretos e no computador. Todos os testes foram conduzidos em extinção.

Relações Testadas com Materiais Concretos. Um protocolo foi organizado com diferentes tarefas. A tarefa era apresentava simultaneamente com as instruções (ambas descritas no protocolo) e registrava-se cada resposta. As relações testadas incluíram os comportamentos de contagem, numerosidade, noção de quantidade (maior, menor e igual), nomeação e identificação de valores monetários. Trinta tarefas foram avaliadas, sendo atribuído um ponto para 
cada resposta correta. O desempenho foi calculado em porcentagem de acertos. Cartões com numerais e bolinhas, moedas e notas verdadeiras, bem como preços impressos no papel foram utilizados para avaliar as relações.

Nas tentativas de escolha de acordo com o modelo com construção de respostas (CRMTS), o estímulo modelo foi apresentado sobre a mesa e permanecia presente enquanto o participante fazia tantas escolhas quantas considerasse necessária. Após a construção da resposta e a sinalização do término da tarefa por parte do participante ("acabei"), o experimentador registrava, de forma abreviada, no espaço destinado do protocolo, o valor de moeda (por exemplo, 1c, $5 c, 10 c$ ) ou nota (por exemplo, 1R, 5R, 10R) selecionada.

Relações Testadas no Computador. Diferentes relações entre estímulos e entre estímulos e respostas foram avaliadas através de tarefas preparadas no computador.

As sessões foram programadas com número igual de tentativas para cada relação testada, intercaladas randomicamente, de forma que nenhum estímulo correspondente à escolha correta se localizasse na mesma posição para mais de duas tentativas consecutivas. Essas sessões foram conduzidas com o auxílio do programa computacional Mestre ${ }^{\circledR}$ (Goyos \& Almeida, 1994), programadas com 20 tentativas, sendo duas para cada um dos valores de um a dez.

Procedimento de Registro das Respostas. Nas tarefas de escolha de acordo com o modelo, o estímulo modelo era apresentado até que o participante tocasse o modelo disposto na metade superior do monitor. Ao toque sobre o estímulo modelo, como uma resposta de observação, apresentavam-se imediatamente em seguida, com atraso zero, os estímulos de escolha. O participante escolhia um deles, tocando-o. Ao toque sobre o estímulo escolha, o experimentador pressionava a tecla "1", "2" ou "3" do teclado numérico, correspondente à posição do estímulo escolhido, o que registrava automaticamente a resposta num arquivo gerado pelo próprio programa.

Nas tarefas de nomeação e construção de respostas, o experimentador pressionava a tecla "1" do teclado numérico para a resposta correta ou a tecla " 3 " para a incorreta, registrando, assim, a resposta num arquivo gerado pelo próprio programa.

Procedimento de Análise de Dados. $O$ desempenho dos participantes foi analisado a partir dos dados apresentados no relatório emitido pelo computador. Verificou-se a porcentagem de acertos em cada relação, a porcentagem de escolhas consistentes com a formação de classes de equivalência, o número de sessões necessárias e o tempo gasto para a aquisição das relações condicionais. A formação de classes de equivalência foi definida a partir do critério de desempenho de escolhas consistentes para cada classe igual ou superior a $90 \%$.

\section{Resultados e discussões}

Estudo $\mathbf{l}^{3}$. Dez jovens com deficiência intelectual, com idades entre 12 e 32 anos, alunos em tempo parcial

3 O participante JES não fez parte do Estudo I. em escola de Educação Especial, ingressaram no estudo, que foi conduzido em uma sala da própria escola destinada exclusivamente para uso da pesquisa. O método de ensino foi baseado em discriminação condicional com tarefas de escolha de acordo com o modelo, formação de classes de equivalência e redes de discriminações condicionais, incluindo emparelhamento de componentes e construção de respostas. Todas as tentativas de escolhas de acordo com o modelo incluíram estímulos auditivos e visuais, apresentados por um computador, o qual também registrava e salvava os resultados em arquivos.

Os estímulos experimentais foram numerais impressos $(1,5,10,25,50$ e 100), figura de moedas apresentadas em cores e tamanhos originais e os respectivos valores numéricos e monetários ditados.

Após a avaliação inicial de todos os participantes com o pré-teste das relações selecionadas para esse Estudo, o treino foi iniciado com o primeiro participante. Quando este atingiu o critério de $90 \%$ de escolhas corretas, o treino foi introduzido para o segundo participante e assim por diante. O treino foi iniciado com a relação de identidade numeral impresso-numeral impresso, seguido do emparelhamento do numeral ditado com numeral impresso e valor monetário ditado com figura de moeda. Em seguida, os participantes foram testados para verificar a emergência de relações de equivalência: moeda com numeral impresso e numeral impresso com moeda. O treino seguinte consistiu do emparelhamento de componentes da adição $(1+1+1+1+1$, $5+5,10+10+5,25+25,50+50$ ) com o resultado da operação. Testes de generalização foram conduzidos com materiais e valores diferentes, em tarefas sobre a mesa com construção de respostas e moedas verdadeiras, e em situação de compra simulada. Durante a compra simulada, o participante selecionava moedas de um conjunto para compor o valor correspondente ao preço impresso no item desejado. A Figura 1 ilustra a primeira rede de relações.

Os resultados do pré-teste indicaram que cinco dos participantes apresentaram desempenhos semelhantes com escores elevados e os outros cinco apresentaram maiores dificuldades. Nas tarefas com material concreto, as maiores dificuldades estiveram relacionadas à contagem de objetos em sequência, nomeação de moedas, notas e preços, construção de respostas a partir da moeda ou do valor monetário ditado. Nas tarefas no computador, as maiores dificuldades foram nas tarefas de relacionar conjuntos com numeral impresso, numeral impresso com figura de moeda e vice-versa, emparelhar preço impresso com moedas e notas e na tarefa de emparelhar componentes da adição com numeral impresso.

O ensino da relação de identidade numeral impressonumeral impresso foi desempenhado com critério por todos os participantes. Os participantes PED, MRO, ACA, ROT, DUD e GBF apresentaram, no repertório de entrada, a relação entre numeral ditado e impresso. A relação valor ditado com figura de moeda foi introduzida e rapidamente eles estabeleceram a relação. A relação entre componentes da adição e o numeral impresso foi adquirida pelos mesmos participantes. Nas sessões de testes, após o ensino direto, os desempenhos 


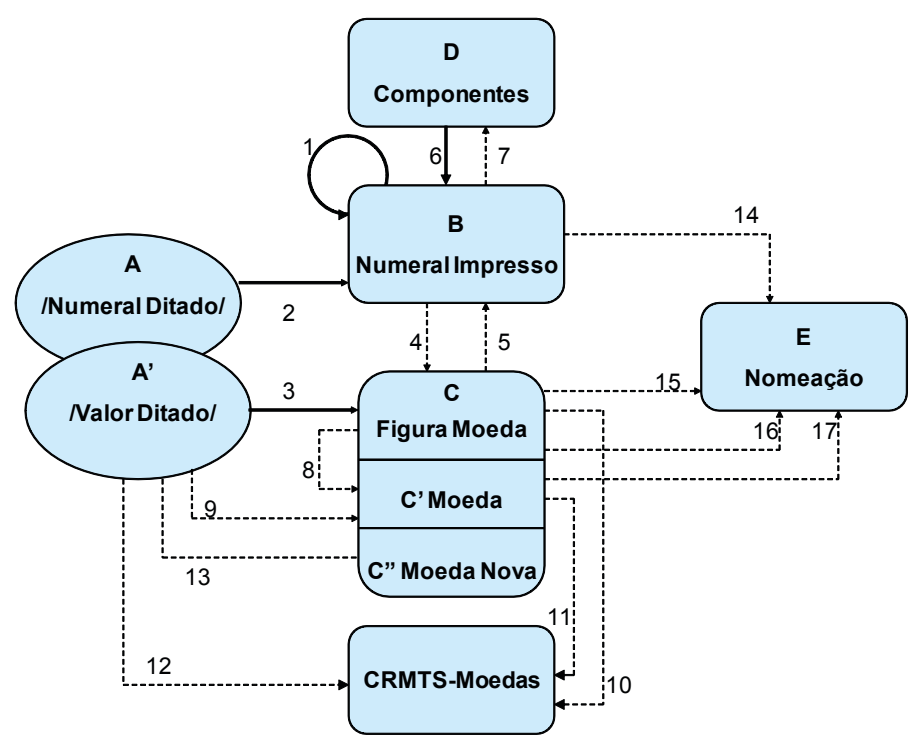

Figura 1. Rede de relações condicionais que compõe o currículo matemático para aquisição do comportamento de manusear dinheiro Estudo I. As caixas indicam os estímulos. As linhas cheias indicam as relações treinadas diretamente e as tracejadas indicam as relações testadas. Os números mostram a sequência de treino e teste.

Fonte: Elaboração dos autores

com escores mais baixos ocorreram nas tentativas de construção de resposta, não havendo distinção se o modelo era a figura da moeda ou o valor ditado. Os participantes GUA e ROA necessitaram de revisões constantes de relações anteriores e de diversos procedimentos adicionais para adquirirem as relações. Esses procedimentos, descritos detalhadamente em Saunders e Spradlin (1989) e Rossit (2003), referiram-se ao desmembramento da tarefa, com a apresentação dos estímulos de dois em dois, e com a redução de três para dois estímulos escolha. Caso o participante não estabelecesse a relação condicional com essa modificação, o segundo tipo de procedimento adicional era aplicado. Nesse caso, o mesmo estímulo modelo era apresentado em todas as tentativas e os estímulos escolhas alteravam-se nas duas posições. Os participantes BRS e $\mathrm{POL}$, que coincidentemente apresentaram desempenhos inferiores no pré-teste, não adquiriram as relações entre os estímulos da classe dos numerais e do valor ditado, apesar dos procedimentos adicionais introduzidos.

Concluiu-se que PED, MRO, ACA, ROT, DUD e GBF adquiriram as habilidades monetárias via procedimento de escolha de acordo com o modelo, incluindo emparelhamento arbitrário, componentes da adição e resposta construída. 0 ensino de habilidades monetárias através do computador mostrou-se eficiente pois, num período de tempo relativamente curto, com tempo de instrução variando de cinco a 40 horas, os participantes aprenderam as quatro relações ensinadas diretamente e 13 novas relações emergiram.
A quantidade de sessões variou de 22 (PED, MRO, ACA, ROT, DUD e GBF) a 75 (GUA, ROA, BRS) e POL não conclui essa etapa. Para mais da metade dos participantes, os que apresentaram melhor desempenho no pré-teste, o procedimento foi eficaz. Para os demais, entretanto, aqueles que mostraram desempenhos mais baixos no préteste, o procedimento foi mais longo para produzir efeitos similares. As relações entre numeral impresso, figura de moedas, moeda verdadeira, assim como o desempenho na construção de respostas, emergiram para aqueles que apresentaram melhor desempenho no pré-teste e no ensino direto. Considerando que a rede de relações condicionais envolvida no ensino de habilidades monetárias é complexa e extensa, e as características da aprendizagem de pessoas com deficiência intelectual, é importante entender quais são os efeitos de uma dada relação sobre a emergência de outras e, assim, identificar melhores caminhos para ensinar habilidades numéricas e monetárias para esta população.

Quanto à emergência da relação entre numerais impressos, figura de moedas e moedas verdadeiras, é possível que essa tenha sido determinada pelo controle exercido pelas diferenças parciais dos estímulos, como a cor, o tamanho e a característica física dos estímulos (numerais, imagens ou materiais concretos). Apesar das diferenças, o valor monetário recebia a mesma denominação em qualquer uma das condições, o que pode ter interferido no desempenho. De acordo com Hübner (1990), as unidades menores que 
compõem as relações ensinadas podem adquirir controle sobre o comportamento textual, então, recombinandose essas unidades, pode-se obter a generalização dos estímulos para outras classes equivalentes.

Uma das questões investigadas foi se a relação condicional entre componentes da adição e o resultado expresso pelo numeral impresso poderia ser transferida para moedas, também no sentido inverso ao treinado. A tarefa requerida consistiu em construir a resposta com moedas verdadeiras a partir do preço impresso ou do valor monetário ditado. Essa relação foi problemática nos testes de generalização em situação de compra simulada, tendo emergido somente para alguns participantes. Apesar disso, tem-se a evidência de que outras relações foram aprendidas.

Saunders, Saunders, Kirby e Spradlin (1988) relatam que discriminações condicionais aprendidas por ensino direto facilitam a aquisição das discriminações seguintes. Nesse caso, pode-se indagar se o treino de discriminações condicionais em tarefas de escolha de acordo com o modelo faria emergir o comportamento de escolha de acordo com o modelo com construção de respostas (CRMTS) com moedas verdadeiras.

Como a construção de respostas foi a principal relação presente nas situações de compras e a que se mostrou mais problemática no Estudo I, elaborou-se o Estudo II, a fim de gerar equivalência entre conjunto de moedas e preço impresso.
O Estudo II foi delineado com o objetivo de verificar se o desempenho de construção de respostas em tarefas monetárias emergiria a partir do ensino das relações condicionais entre conjunto de moedas e preço impresso.

Tais relações, entretanto, implicam em tratar estímulos fisicamente diferentes como equivalentes. Stoddard e cols. (1989) descreveram esse evento com o termo "equivalência monetária" para referirem-se, informalmente, às relações entre estímulos de igual valor monetário, contudo com configurações diferentes. A equivalência monetária ocorre, por exemplo, quando o participante emparelha conjunto de moedas com uma moeda única ou com o preço impresso. A verificação da formação de classe de estímulos equivalentes provém quando o participante emparelha uma outra combinação de moedas com o preço, sem treino explícito. Isso leva à evidência de que as relações emparelhadas são equivalentes, mas a prova formal requer testes controlados.

Estudo II. Com o intuito de expandir a rede, um outro conjunto de relações alimenta o currículo inicial, com o objetivo de analisar a aquisição de relações entre figura de moeda- preço impresso e conjunto de moedas-preço impresso e avaliar o desempenho emergente em tarefas de construção de respostas.

Participaram deste estudo sete jovens com deficiência intelectual (MRO, PED, DUD, ROT, GBF JESeBRS). As seguintes habilidades estavam presentes no repertório desses jovens: emparelhar números e moedas com seus correspondentes ditados; nomear moedas; emparelhar estímulos idênticos; emparelhar componentes com o número impresso equivalente.

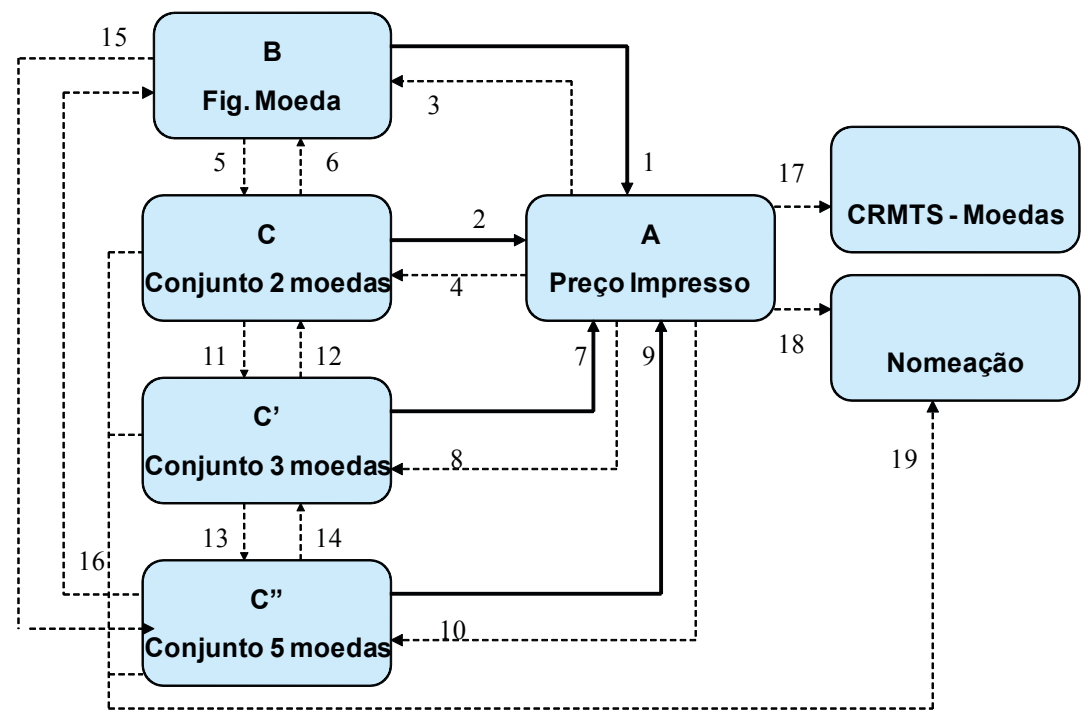

Figura 2. Rede de relações condicionais que expande o currículo matemático para aquisição do comportamento de manusear dinheiro - Estudo II. As caixas indicam os estímulos. As linhas cheias indicam as relações treinadas diretamente e as tracejadas indicam as relações testadas. Os números mostram a sequência de treino e teste.

Fonte: Elaboração dos autores 
As sessões foram conduzidas através de um computador, que apresentava os estímulos, registrava e salvava os resultados em arquivos. Os estímulos experimentais foram as figuras de moedas $(1 \phi, 5 \phi, 10 \phi, 25 \phi \mathrm{e}$ $50 \phi$ ), conjuntos de duas, três e cinco moedas para os valores de $5,10,15,20,25,30$ e 50 centavos e preços impressos. As relações treinadas e testadas estão na Figura 2.

Os resultados demonstraram que, de quatro relações ensinadas diretamente, 13 novas relações emergiram provavelmente em função do treino. Também foram verificadas oito relações que generalizaram para condições diferentes, nas quais foram utilizadas moedas verdadeiras, valores monetários não treinados e conjuntos de moedas diferentes das utilizadas no ensino direto, e para situação de compra simulada.

O ensino através de escolha de acordo com o modelo mostrou-se eficiente para a emergência da construção de respostas para os cinco participantes que completaram as etapas de ensino direto e testes. Outros dois participantes apresentaram maiores dificuldades e necessitaram de diversos procedimentos adicionais para a aquisição das relações condicionais.

Os resultados apontam para a eficácia do procedimento de ensino, vista a aquisição de habilidades complexas num período de tempo reduzido, quando comparado com o tempo de vida e de escolarização. Para concluir as etapas de ensino direto, foram necessárias de dez a 13 sessões para MRO, PED, DUD e ROT. Para GBF, foram necessárias 34 sessões, sendo 20 de treino padrão e 14 de procedimentos adicionais. JES concluiu a sequência de treino com 70 sessões, sendo 28 de treino padrão e 48 de procedimentos adicionais. O participante BRS necessitou de 80 sessões para estabelecer as relações condicionais propostas neste estudo, sendo 30 sessões de treino padrão e 50 de procedimentos adicionais. A duração das sessões variou de cinco a 20 minutos, o que nos fornece um tempo de instrução que varia de uma a 30 horas de ensino direto. Quatro participantes (MRO, PED, DUD e ROT) necessitaram de apenas uma sessão para atingirem o critério em cada uma das relações condicionais determinadas para o Estudo II, totalizando apenas uma hora de instrução direta; GBF cumpriu as etapas de ensino direto em 12 horas; JES, em 25 horas; e BRS, em 30 horas. Esse tempo de instrução é mínimo quando comparado ao tempo de vida e de escolarização, regular ou especial, dos participantes.

Os resultados aqui obtidos são satisfatórios, pois a maioria dos participantes adquiriu relações complexas, que não estavam presentes em seu repertório inicial. Embora as relações não tenham emergido em sua totalidade para todos os participantes, pode-se verificar mudanças importantes em seus desempenhos, o que possivelmente se refletirá em maior independência para esses participantes em outras situações que requeiram habilidades semelhantes.

Numa análise geral do Estudo II, percebe-se que, de quatro relações ensinadas diretamente, mais de 15 novas relações emergiram em função do treino para a maioria dos participantes. Também foram verificadas oito relações que foram expandidas para condições diferentes - nas quais foram utilizadas moedas verdadeiras, valores monetários não treinados e conjuntos com combinações diferentes das utilizadas durante o ensino direto - e para situação de compra simulada. Um dos aspectos importantes no ensino de pessoas com deficiência intelectual é a possibilidade de dotá-los com habilidades que permitam atuar de forma positiva na comunidade.

Os dados do presente estudo confirmam a economia de ensino que se obtém quando se utiliza o paradigma de equivalência de estímulos e essa é a principal justificativa de sua utilização nessa pesquisa, a qual contém uma rede extensa e complexa de relações a serem ensinadas.

Tendo obtido resultados importantes na aquisição e generalização de relações condicionais complexas na população em estudo, avançou-se na formação e expansão das classes de equivalência no comportamento matemático com o ensino das novas relações delineadas para o Estudo III.

O Estudo III teve como objetivo verificar se o controle estabelecido através das relações previamente treinadas com moedas poderia ser transferido para relações envolvendo notas (valores em reais). Através do procedimento de escolha de acordo com o modelo, utilizaram-se conjuntos com uma, duas, três ou cinco notas a serem emparelhadas com o preço impresso.

Estudo III. Alguns autores (Goyos \& Freire, 2000; Saunders, Drake \& Spradlin, 1999; Green \& Saunders, 1998; Stromer \& cols., 1992; Stoddard \& cols., 1989) afirmam que, para expandir uma classe de estímulos, inserindo novos membros, é necessário apenas que o novo estímulo seja associado a um único membro da classe e não a cada um de seus elementos. A economia obtida com esse tipo de paradigma se dá, então, em dois momentos: inicialmente, no planejamento do ensino e, posteriormente, na formação da classe em expansão.

A expansão do currículo matemático envolveu a inclusão de novas relações e novos estímulos. Cinco participantes (MRO, DUD, PED, ROT, GBF) que demonstraram a aquisição das relações contidas nos Estudos I e II prosseguiram com o ensino das novas relações contidas na Figura 3. Os estímulos experimentais foram os numerais impressos 1, 5, 10, 25, 50 e 100, figuras e conjuntos de notas, preço impresso e os respectivos valores ditados. O ambiente experimental e os procedimentos de ensino permaneceram os mesmos descritos anteriormente. A rede de relações foi ampliada substituindo-se os estímulos moedas por notas.

Para os participantes que desempenharam com critério as relações previamente testadas (MRO e DUD), nenhuma sessão de ensino direto foi conduzida. Para PED, foi necessária apenas uma sessão para que o critério fosse atingido para as relações C'A e C"A. ROT atingiu o critério com apenas uma sessão para cada uma das relações. Para GBF, que apresentou escores mais baixos durante o préteste, a relação mais problemática foi BA (figura nota-preço impresso), a qual requereu a introdução de procedimentos adicionais; as demais relações foram adquiridas em uma 


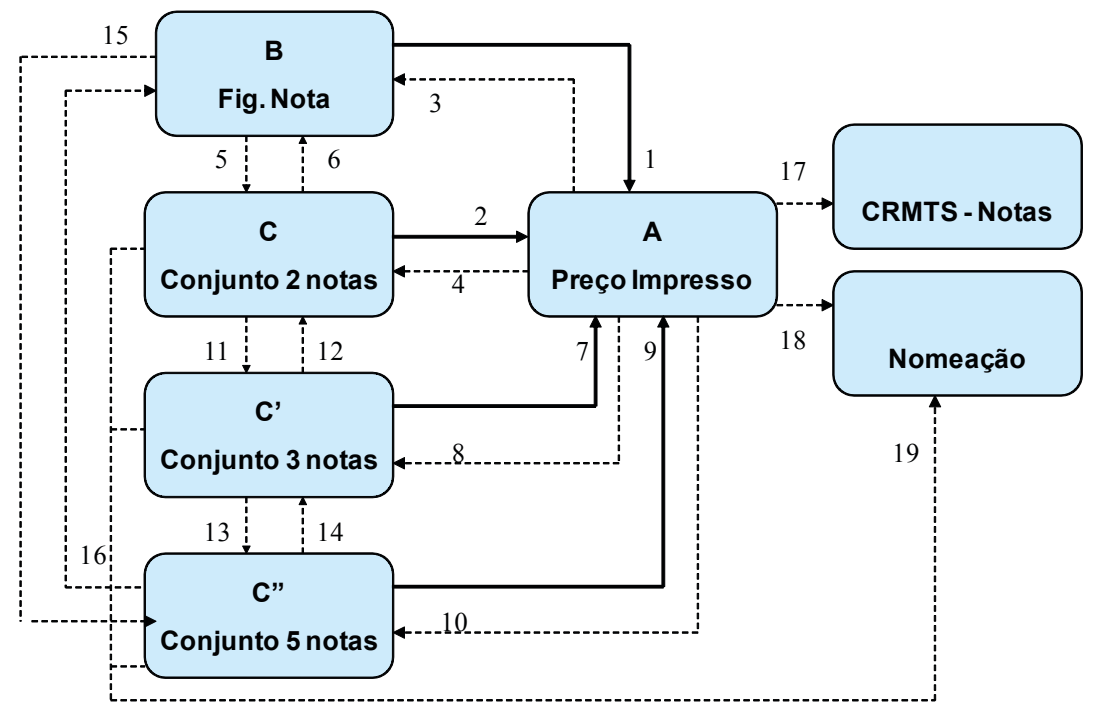

Figura 3. Rede de relações condicionais que expande o currículo matemático para aquisição do comportamento de manusear dinheiro - Estudo III. As caixas indicam os estímulos. As linhas cheias indicam as relações treinadas diretamente e as tracejadas indicam as relações testadas. Os números mostram a sequência de treino e teste.

Fonte: Elaboração dos autores

ou duas sessões. O tempo de instrução direta neste estudo variou de zero a três horas e meia.

Um aspecto interessante a ser discutido diz respeito à eficácia dos procedimentos adicionais (Saunders \& Spradlin, 1989) utilizados para o ensino de relações problemáticas para alguns participantes. Esses procedimentos tiveram a finalidade de desmembrar a tarefa em passos mais simples de tal forma que os estímulos tornavam-se discrimináveis uns dos outros. Isso parece ter contribuído para as discriminações e para o consequente estabelecimento das relações condicionais.

Um outro aspecto diz respeito à expansão da classe de equivalência. Produzir novos comportamentos sem treino explícito é uma das principais características do paradigma de equivalência de estímulos. Essa característica é evidenciada na formação de classes de estímulos, o que significa que, quando um novo estímulo é estabelecido como equivalente a qualquer outro membro de dada classe, aquele estímulo torna-se equivalente a todos os outros membros daquela classe, sem novo treino (Spradlin \& cols., 1974; Stoddard \& cols., 1987; Stoddard \& cols., 1989). Os dados obtidos neste estudo confirmam a expansão da classe de estímulos equivalentes em relações monetárias, em pessoas com moderado e severo comprometimento intelectual.

O comportamento matemático envolve um número ilimitado de classes e de relações entre diferentes conjuntos de estímulos, sendo que apenas uma subclasse desses conjuntos representa o universo monetário. Esta é, talvez, uma das razões pelas quais a matemática é considerada uma disciplina de difícil aprendizagem. Por esta razão, justificase a elaboração de procedimentos e programas de ensino eficazes. A formação de classes de estímulos equivalentes em matemática é uma característica importantíssima, vista a viabilidade da redução da quantidade de relações a serem ensinadas diretamente e a possibilidade da emergência de novas relações. Essa economia é uma das principais vantagens do uso do paradigma de equivalência de estímulos no ensino de habilidades complexas para pessoas que apresentam déficits na aprendizagem, como é o caso dos participantes desta pesquisa.

A maioria das pesquisas na área de equivalência de estímulos (Sidman, Kirk \& Willson-Morris, 1985; Sidman \& Tailby, 1982) tem estudado a formação de classes utilizando três ou quatro relações condicionais com indivíduos com e sem atraso de desenvolvimento. Na presente pesquisa, é demonstrada a formação de classes extensas entre estímulos-estímulos e estímulos-resposta no comportamento matemático para pessoas com deficiência intelectual. Os resultados aqui encontrados indicam que os participantes formaram classes de estímulos equivalentes, derivadas provavelmente de treinos anteriores, as quais foram generalizadas para valores não treinados, para arranjos diferentes e para situação simulada de compra. Além disso, é importante salientar que é possível expandir ainda mais essas classes, por meio do acréscimo de novos estímulos às classes já existentes.

Numa análise geral do Estudo III, percebeu-se que, de quatro relações ensinadas diretamente, 15 novas 
relações emergiram, provavelmente em função dos treinos anteriores. Verificou-se, também, que oito novas relações foram generalizadas para condições diferentes, nas quais utilizaram-se notas verdadeiras em testes com valores monetários não treinados e conjunto de notas diferentes; e para situação de compra simulada. É importante ressaltar que as relações que emergiram confirmam a economia natural do paradigma de equivalência de estímulos durante o processo de ensino-aprendizagem das habilidades monetárias.

A questão investigada no Estudo III, sobre a possibilidade do controle estabelecido através das relações previamente treinadas, utilizando moedas como estímulo, ser transferido para o estímulo notas, foi respondida com sucesso. A maioria das relações foi transferida para o novo estímulo com número reduzidíssimo de sessões de ensino direto, o que evidencia a presença do controle previamente estabelecido. Para os participantes que necessitaram de ensino direto, pode-se inferir que o controle estava parcialmente presente, pois as relações foram adquiridas rapidamente. Talvez a questão da novidade e da complexidade do estímulo visual, com diversas notas no conjunto, tenha interferido negativamente no desempenho inicial, quando as relações foram pré-testadas.

Em função dos procedimentos utilizados, a emergência do desempenho em tarefas com construção de respostas foi evidenciada no Estudo III, sem treino prévio. Para os participantes que apresentaram melhor desempenho no pré-teste, o procedimento foi muito eficaz. Apesar da construção de resposta ser uma tarefa de natureza complexa, isso parece não ter sido um obstáculo para que os participantes com deficiência intelectual apresentassem desempenhos de $100 \%$, não só nas tarefas apresentadas pelo computador, mas também com material concreto e em situação de compra simulada. Os resultados mostraramse positivos, pois os participantes aprenderam as relações matemáticas através dos procedimentos utilizados e outras emergiram sem ensino direto.

De acordo com Catania (1999) e Souza (1997), o paradigma de equivalência de estímulos identifica classes de respostas com propriedades em comum, de modo que tenham efeitos ambientais similares. Tendo como justificativa a possibilidade de transferência do controle de estímulos para a emergência de novas relações, o Estudo IV foi delineado para avaliar o efeito dos três estudos anteriores sobre a generalização de valores compostos por reais e centavos, com apresentação simultânea de notas e moedas.

Nos estudos anteriores, os estímulos foram apresentados ora em centavos, ora em reais. O interesse em delinear o Estudo IV partiu da indagação sobre a possibilidade dos participantes com deficiência intelectual relacionarem cumulativamente os conteúdos anteriormente adquiridos, ou seja, responderem para estímulos expressos em reais e centavos simultaneamente, sem treino explícito.

Estudo IV. Cinco participantes ingressaram nesse estudo (MRO, PED, ROT, DUD, GBF). Todos demonstraram desempenhos acima de $90 \%$ nas relações pré-testadas para a rede de relações envolvendo reais e centavos simultaneamente, não sendo necessária nenhuma sessão de ensino direto. A Figura 4 ilustra a rede utilizada no Estudo IV.

Os resultados mostraram que a aquisição efetiva das relações envolvidas no Estudo IV pode ter sido facilitada pela experiência acumulada e progressiva derivada dos treinos anteriores, a qual possibilitou a discriminação de componentes alvos. Esses resultados são importantes, pois indicam que a estrutura do currículo proposto como rede de relações contribuiu para a emergência de novas

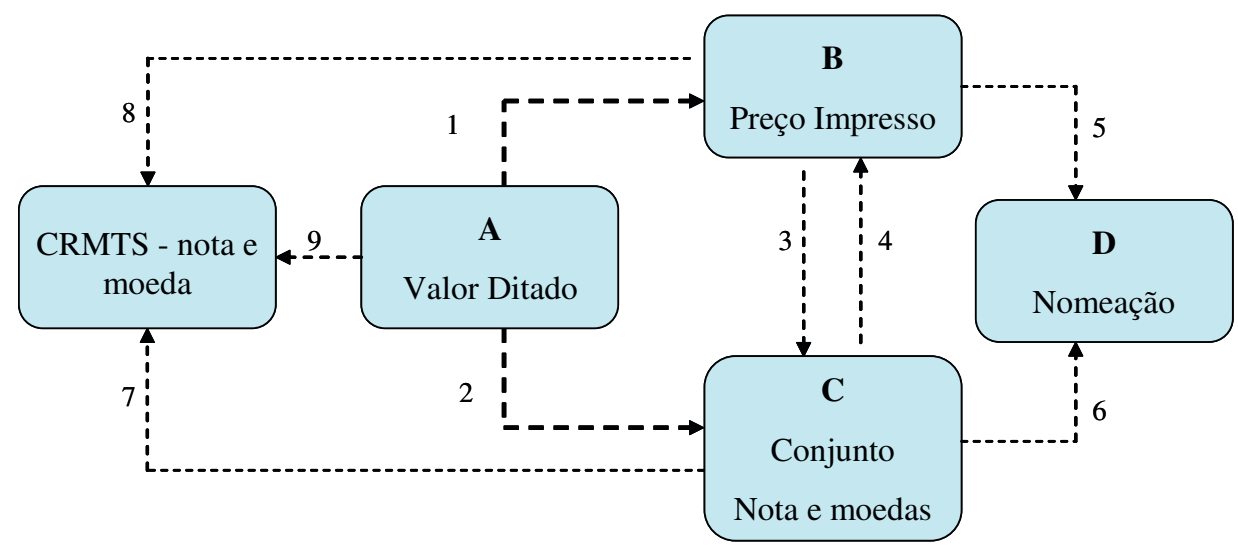

Figura 4. Rede de relações condicionais que completa o currículo matemático para aquisição do comportamento de manusear dinheiro - Estudo IV. As caixas indicam os estímulos. As linhas cheias indicam as relações treinadas diretamente e as tracejadas indicam as relações testadas. Os números mostram a sequência de treino e teste.

Fonte: Elaboração dos autores 
relações, sem que houvesse necessidade de ensiná-las diretamente. Neste procedimento, um novo membro foi adicionado ao conjunto de estímulos para ser discriminado dos outros previamente dominados, o que é denominado de programação cumulativa (Mayfield \& Chase, 2002).

Mayfield e Chase (2002) argumentam que a justaposição de diferentes tipos de problemas, em uma programação cumulativa de ensino, possibilita a aprendizagem de múltiplas discriminações. Esses autores encontraram maior acurácia em tarefas de resolução de problemas para estudantes que receberam instruções que incorporaram a prática cumulativa, utilizando uma mistura de habilidades previamente treinadas, acrescidas de novos conteúdos gradativamente.

A emergência dessas novas relações com arranjo diferente dos estímulos dentro do conjunto, valores diferentes e em situação de compra simulada justifica a efetividade do procedimento de ensino utilizado.

Os resultados encontrados nesse último estudo são consistentes com os achados da literatura e se opõem à visão tradicional da aprendizagem de pessoas com deficiência intelectual, pois se verificou que os participantes transferiram o controle de estímulo estabelecido nos treinos anteriores para os novos estímulos e situações, sem que houvesse a necessidade de ensino direto.

A emergência das relações que foram ensinadas prévia e separadamente, envolvendo conjunto de notas e moedas apresentadas simultaneamente e composto por classes de estímulos diferentes, reitera uma das principais características do paradigma de equivalência de estímulos, que é a economia do tempo e do percurso no ensino de novas relações quando comparado aos procedimentos de ensino tradicionais utilizados nas escolas. Neste caso, foi necessário apenas incluir um novo membro à classe de estímulos-respostas existente e constatou-se a sua integração com os demais membros. As relações ensinadas nos estudos anteriores podem ter assumido a função de pré- requisitos para que o desempenho pudesse ter emergido neste contexto. Tais resultados evidenciam a expansão das classes de equivalência em pessoas com deficiência intelectual.

Analisando-se o currículo construído, constata-se que a formação e a expansão da rede de relações ocorreu passo a passo. No total, 13 relações foram ensinadas diretamente e 58 novas relações testadas entre simetria, transitividade e generalização para estímulos, valores e situação diferentes. Em média, foram necessárias 44 sessões de aproximadamente dez minutos cada para que os participantes completassem o treino e demonstrassem a formação das classes de equivalência $(1,5,10,25,50,100)$ com 11 conjuntos de estímulos (palavras ditadas, numerais impressos, componentes da adição, valores ditados, moedas, conjunto de moedas, preços, moedas novas, notas, conjunto de notas, conjunto de notas/moedas), além da emergência da nomeação e da construção de respostas para 23 novos valores. A Tabela 2 mostra a quantidade de sessões e o tempo necessário para a aquisição das relações condicionais.

Testes foram aplicados imediatamente após cada relação ensinada e follow-up realizado após três e seis meses da finalização de cada Estudo para avaliar a manutenção das relações no repertório dos participantes, as quais se mantiveram presentes em seus repertórios individuais.

Os resultados demonstraram a eficácia do currículo sugerido e dos procedimentos de ensino utilizados, constatada a aquisição de habilidades complexas num período de tempo reduzido quando comparado ao tempo de vida e de escolarização e a manutenção das relações adquiridas ao longo do tempo. Uma ampla e complexa rede de relações matemáticas foi ensinada a partir do treino direto de apenas algumas dessas relações. A informatização do ensino agilizou o processo de ensino-aprendizagem, aumentou a confiabilidade dos dados e controlou as contingências, de forma a ensinar exatamente conforme o planejado.

Tabela 2. Quantidade de Sessões e Tempo de Instrução

\begin{tabular}{ccccccc}
\hline \multirow{2}{*}{ Participantes } & Idade & Escolarização & \multicolumn{5}{c}{ No $^{\text {(anos,mesones /Instrução (hs) }}$} \\
& \multicolumn{2}{c}{ Estudo 1 } & Estudo 2 & Estudo 3 & Estudo 4 \\
\hline MRO & 32 & 28,5 & $23 / 5: 15$ & $10 / 1$ & $0 / 0$ & $0 / 0$ \\
PED & 12,2 & 12 & $24 / 5: 30$ & $11 / 1$ & $4 / 50$ & $0 / 0$ \\
ACA & 21,3 & 17,5 & $23 / 5: 15$ & & & \\
ROT & 18,3 & 13 & $23 / 5: 15$ & $13 / 1: 30$ & $9 / 1: 30$ & $0 / 0$ \\
DUD & 14,8 & 12 & $23 / 5: 15$ & $10 / 1$ & $0 / 0$ & $0 / 0$ \\
GBF & 19,6 & 15 & $22 / 5: 15$ & $34 / 12$ & $15 / 4: 30$ & $0 / 0$ \\
GUA & 16 & 12 & $64 / 30$ & & & \\
ROA & 17,1 & 14,5 & $75 / 40$ & & & \\
BRS & 12,5 & 10 & $74 / 40$ & $80 / 30$ & & \\
POL & 18,3 & 16 & $22 / 10$ & & & \\
JES & 9,10 & 6 & & $70 / 25$ & & \\
\hline
\end{tabular}

Fonte: Elaboração dos autores 


\section{Considerações Finais}

A Matemática está presente em diversas situações do cotidiano. Os números, além de serem uma linguagem de medida, também são necessários para os comportamentos adaptativos de encontrar um endereço, usar um telefone, "ler" horas de um relógio ou mesmo apreciar um jogo de futebol, entre outros.

Tradicionalmente, muitos educadores acham que os alunos com deficiência intelectual esquecem muito do que tem sido previamente ensinado. Um dia eles "sabem" algumas coisas e no dia seguinte eles não lembram mais isso. Existe a crença de que eles podem aprender, mas que há dificuldade em transferir o conhecimento para outras situações ou materiais. A condição de deficiência intelectual tem sido citada como uma variável que proporciona uma aquisição lenta e retenção pobre de discriminações previamente ensinadas. Entretanto, a questão da retenção pobre pode ser atribuída, em grande parte, às falhas na programação instrucional, mais do que às características da deficiência intelectual.

A manutenção dos resultados obtidos ao longo do tempo poderia ser explicada pela aplicabilidade do conhecimento previamente adquirido em outras situações cotidianas e/ou pelo efeito cumulativo dos quatro estudos. Considerando a idade cronológica dos participantes, o tempo de escolarização e os desempenhos evidenciados por ocasião da aplicação dos testes preliminares, pode-se inferir que os resultados obtidos têm relação direta com a proposta de ensino desenvolvida e avaliada. Os históricos de vida das pessoas com deficiência intelectual que participaram desta pesquisa indicam a eficiência dos procedimentos utilizados, que permitiram o estabelecimento de relações condicionais complexas e a aquisição de um repertório matemático que possibilitou desempenhos positivos e independência em tarefas na comunidade.

A proposta do ensino através de rede de relações entre estímulos e entre estímulos e respostas possibilitou a aquisição de conhecimentos passo a passo e a possibilidade de detectar precocemente as dificuldades na aprendizagem. Essa foi uma característica importante que permitiu intervir pontualmente através de procedimentos adicionais apropriados.

O currículo como rede de relações pautou-se no planejamento detalhado e na avaliação cuidadosa e minuciosa de repertório inicial e das aquisições ao longo do processo de ensino e da aprendizagem. O modelo aqui apresentado configura-se como uma estratégia promissora e viável de ser aplicada em ambientes educacionais inclusivos, atendendo às necessidades educacionais de todos os alunos. Cabe, aos educadores, inteirar-se das inovações produzidas na área da Educação Especial e aplicá-las em salas de aula.

Os resultados da sequência de estudos mostraram que participantes com deficiência intelectual formaram classes extensas de estímulos equivalentes e expandiram para valores não treinados e situação simulada de compra. É importante salientar que é possível estender ainda mais essas classes por meio do acréscimo de novos estímulos às classes já existentes. Assim, o objetivo proposto de analisar a aquisição de relações matemáticas envolvidas no comportamento de manusear dinheiro e apresentar o currículo utilizado com pessoas com deficiência intelectual foi atingido, avançou na compreensão dos processos de ensinoaprendizagem e surpreendeu educadores e pesquisadores da área quanto às possibilidades apresentadas e os resultados obtidos.

\section{Referências}

Araújo, P. M. (2004). Comportamento de subtrair com base no paradigma de equivalência de estímulos: um estudo com deficientes intelectuais. Dissertação de Mestrado, Universidade Federal de São Carlos, São Carlos, São Paulo.

Carmo, J. S. (1997). Aquisição do conceito de número em crianças pré-escolares através do ensino de relações condicionais e generalização. Dissertação de Mestrado, Universidade Federal do Pará, Belém, Pará

Catania, A. C. (1999). Aprendizagem: comportamento e cognição (D. G. de Souza \& cols., Trad., 4a ed.). Porto Alegre: Artes Médicas Sul.

De Lèon, N. P. A. (1998). Aquisição de habilidades básicas de matemática através da formação de equivalência em crianças pré-escolares. Dissertação de Mestrado, Universidade Federal de São Carlos, São Carlos, São Paulo.

Escobal, G., \& Goyos, C. (2008). Análise das variáveis determinantes do comportamento de escolha entre alternativas de trabalho em adultos com deficiência mental. Revista Brasileira de Análise do Comportamento, 4(1), 71-87.

Goyos, C., \& Almeida, J. C. B. (1994). Mestre (Versão 1.0) [Computer software]. São Carlos, SP: Mestre Software.

Goyos, C., \& Freire, A. F. (2000). Programando ensino informatizado para indivíduos com deficiência intelectual. Em E. J. Manzini (Org.), Educação Especial: Temas Atuais (pp. 57-73). Marília: Unesp Marília Publicações.

Green, G. (1992). Stimulus control technology for teaching number/ quantity equivalences. Proceedings of the Conference os the National Association for Autism (p. 51-64). Melbourne, Australia: Vistoria Autistic Children's, \& Adults' Association, Inc.

Green, G., \& Saunders, R. R. (1998). Stimulus Equivalence. Em A. K. Lattal \& M. Perone (Eds.), Handbook of Researchs Methods in Human Operant Behavior (pp. 229-262). New York: Plenum Press.

Hübner, M. M. (1990). Estudos em relações de equivalência: uma contribuição à investigação do controle por unidades mínimas na aprendizagem de leitura com pré-escolares. Tese de Doutorado, Universidade de São Paulo, São Paulo.

Mayfield, K. H., \& Chase, P. N. (2002). The effects of cumulative practice on mathematics problem solving. Journal of Applied Behavior Analysis, 35, 105-123.

Ministério da Educação e do Desporto. Secretaria de Educação Fundamental. (1998). Parâmetros Curriculares Nacionais: Matemática. Brasília: MEC/ SEF.

Monteiro, G., \& Medeiros, J. G. (2002). A contagem oral como prérequisito para a aquisição do conceito de número com crianças pré-escolares. Estudos de Psicologia, 7(1), 73-90. 
Pires, C. M. C. (2000). Currículos de matemática: da organização linear à idéia de rede. São Paulo: FTD.

Prado, P. S. T. (2001). Ensinando o conceito de número: contribuições do paradigma de rede de relações. Tese de Doutorado, Universidade de São Paulo, São Paulo.

Resnick, L. B., Wang, M. C., \& Kaplan, J. (1973). Task analysis in curriculum design: A hierarchically sequenced introductory mathematics curriculum. Journal of Applied Behavior Analysis, 6, 679-710.

Rossit, R. A. S. (2003). Matemática para deficientes intelectuais: contribuições do paradigma de equivalência de estímulos para o desenvolvimento e avaliação de um currículo. São Carlos: EDUFSCar.

Rossit, R. A. S. (2004). Ensino de deficientes intelectuais: avaliação e planejamento. Em PRIMEIROS PASSOS em Análise do Comportamento e Cognição (Vol. 2, pp. 89-98). Santo André, SP : ESETec

Rossit, R. A. S., \& Ferreira, P. R. S. (2003). Equivalência de estímulos e o ensino de pré-requisitos monetários para pessoas com deficiência intelectual. Temas em Psicologia da SBP, 11, 97-106.

Saunders, R. R., Drake, K. M., \& Spradlin, J. E. (1999). Equivalence class establishment, expansion, and modification in preschool children. Journal of the Experimental Analysis of Behavior, 71, 195-214.

Saunders, R. R., Saunders, K. J., Kirby, K. C. \& Spradlin, J. E. (1988). The merger and development of equivalence classes by unreinforced conditional selection of comparison stimuli. Journal of the Experimental Analysis of Behavior, 50, 145-162.

Saunders, K. J., \& Spradlin, J. E. (1989). Conditional discrimination in mentally retarded adults: The effect of training the component simple discriminations. Journal of the Experimental Analysis of Behavior, 52, 1-12.
Sidman, M., Kirk, B., \& Willson-Morris, M. (1985). Six-member stimulus classes generated by conditional discrimination procedure. Journal of the Experimental Analysis of Behavior, 43, 21-42.

Sidman, M., \& Tailby, W. (1982). Conditional discrimination vs. matching to sample: An expansion of the testing paradigm. Journal of the Experimental Analysis of Behavior, 37, 5-22.

Souza, D. G. (1997). A evolução do conceito de contingência. Em R. A. Banaco (Org.), Sobre Comportamento e Cognição (p. 88-105). São Paulo: ARBytes Editora.

Spradlin, J. E., Cotter, V. W., Stevens, C., \& Friedman, M. (1974). Performance of mentally retarded children on prearithmetic tasks. American Journal of Mental Deficiency, 78, 397-403.

Stoddard, L. T., Bradley, D. P., \& Mcllvane, W. J. (1987). Stimulus control of emergent performances: teaching money skills. Em J. A. Mulick, \& R. F. Antonak (Eds.), Transitions in Mental Retardation Issues in Therapeutic Intervention (Vol. 2, pp. 113-149). Norwood, NJ: Ablex Publishing Co.

Stoddard, L. T., Brown, J., Hurlbert, B., Manoli, C., \& Mcllvane, W. J. (1989). Teaching money skills through stimulus class formation, exclusion and component matching methods: Three case studies. Research in Developmental Disabilities, 10, 413-439.

Stromer, R., Mackay, H. A., \& Stoddard, L. T. (1992). Classroom applications of stimulus equivalence technology. Journal of Behavioral Education, 2, 225-256.

Teberosky, A., \& Tolchinsky, L. (2002). Além da alfabetização: a aprendizagem fonológica, ortográfica, textual e matemática. São Paulo: Editora Ática.

\section{Sobre os Autores}

Rosana Aparecida Salvador Rossit (rorossit@hotmail.com)

Universidade Federal de São Paulo

Celso Goyos (celsogoyos@hotmail.com)

Universidade Federal de São Carlos

\section{Correspondência}

Rosana Ap. Salvador Rossit

Rua Bolívia, 260 - Parque Estância Suiça

13566-680 - São Carlos - SP

\section{Agradecimento}

Pesquisa apoiada pela FAPESP.
Recebido em: 25/01/2008

Reformulado em: 12/01/2010

Aprovado em: 14/01/2010 